\title{
The relationships between toad behaviour, antipredator defences, and spatial and sexual variation in predation pressure
}

\author{
Francisco Javier Zamora-Camacho ${ }^{\text {Corresp. 1,2 }}$ \\ 1 Departamento de Sistemas Físicos, Químicos y Naturales, Universidad Pablo de Olavide, Seville, Spain \\ 2 \\ 2 Departamento de Biodiversidad, Ecología y Evolución, Universidad Complutense de Madrid, Madrid, Spain \\ Corresponding Author: Francisco Javier Zamora-Camacho \\ Email address: zamcam@ugr.es
}

Background. Animal behaviour is under strong selection. Selection on behaviour, however, might not act in isolation from other fitness-related traits. Since predators represent outstanding selective forces, animal behaviour could covary with antipredator defences, such that individuals better suited against predators could afford facing the costs of riskier behaviours. Moreover, not all individuals undergo equivalent degrees of predation pressure, which can vary across sexes or habitats. Individuals under lower predation pressure might also exhibit riskier behaviours.

Methods. In this work, I tested these hypotheses on natterjack toads (Epidalea calamita). Specifically, I gauged activity time, exploratory behaviour and boldness in standard laboratory conditions, and assessed whether they correlated with body size and antipredator strategies, namely sprint speed, parotoid gland area and parotoid gland colour contrast. Additionally, I compared these traits between sexes and individuals from an agrosystem and pine grove, since there is evidence that males and agrosystem individuals are subjected to greater predation pressure.

Results. Sprint speed as well as parotoid gland contrast and size appeared unrelated to the behavioural traits studied. In turn, body mass was negatively related to activity time, boldness and exploration. This trend is consistent with the fact that larger toads could be more detectable to their predators, which are mostly gape unconstrained and could easily consume them. As predicted, females exhibited riskier behaviours. Nonetheless, agrosystem toads did not differ from pine grove toads in the behavioural traits measured, despite being under stronger predation pressure. 
2 The relationships between toad behaviour,

3 antipredator defences, and spatial and sexual variation

\section{4 in predation pressure}

5

6 Francisco Javier Zamora-Camacho ${ }^{1,2}$

7

$8{ }^{1}$ Departamento de Sistemas Físicos, Químicos y Naturales. Universidad Pablo de Olavide,

9 Carretera de Utrera km 1, 41080, Seville, Spain.

10

${ }^{2}$ Departamento de Biodiversidad, Ecología y Evolución, Facultad de Ciencias Biológicas, Universidad Complutense de Madrid, C/José Antonio Novais 12, 28040 Madrid, Spain.

Corresponding Author:

Email address: zamcam@ugr.es

\section{Abstract}

Background. Animal behaviour is under strong selection. Selection on behaviour, however, might not act in isolation from other fitness-related traits. Since predators represent outstanding selective forces, animal behaviour could covary with antipredator defences, such that individuals better suited against predators could afford facing the costs of riskier behaviours. Moreover, not all individuals undergo equivalent degrees of predation pressure, which can vary across sexes or habitats. Individuals under lower predation pressure might also exhibit riskier behaviours.

Methods. In this work, I tested these hypotheses on natterjack toads (Epidalea calamita). Specifically, I gauged activity time, exploratory behaviour and boldness in standard laboratory conditions, and assessed whether they correlated with body size and antipredator strategies, 
27 namely sprint speed, parotoid gland area and parotoid gland colour contrast. Additionally, I

28 compared these traits between sexes and individuals from an agrosystem and pine grove, since

29 there is evidence that males and agrosystem individuals are subjected to greater predation

30 pressure.

31 Results. Sprint speed as well as parotoid gland contrast and size appeared unrelated to the

32 behavioural traits studied. In turn, body mass was negatively related to activity time, boldness

33 and exploration. This trend is consistent with the fact that larger toads could be more detectable

34 to their predators, which are mostly gape unconstrained and could easily consume them. As

35 predicted, females exhibited riskier behaviours. Nonetheless, agrosystem toads did not differ

36 from pine grove toads in the behavioural traits measured, despite being under stronger predation

37 pressure.

38

\section{Introduction}

40 Animal behaviour is strongly subjected to selection, and thus represents a fundamental

41 component of fitness (Dingemanse \& Réale, 2005; Dugatkin, 2020). Traits such as sexual

42 selection (Schuett, Tregenza \& Dall, 2010), reproductive success (Zhao et al., 2016),

43 productivity (Biro \& Stamps, 2008), contest outcome (Briffa, Sneddon \& Wilson, 2015), and

44 even mortality (Stamps, 2007), are known to be linked to traits such as boldness (i.e., willingness

45 to engage in activities that involve exposure) or exploratory behaviour (i.e., willingness to

46 investigate a novel environment), although these traits oftentimes exert opposing fitness

47 consequences. Indeed, selection on behaviour can hardly be regarded as directional, since the

48 fitness consequences of behavioural traits are context-dependent (Smith \& Blumstein, 2008;

49 MacPherson et al., 2017). For instance, bold red squirrels (Sciurus vulgaris) survive better in

50 food-restrictive habitats, but worse in sites where food supplies are stable, whereas exploratory 
51 behaviour has a consistent negative relationship with survivorship and female reproductive 52 success across habitats (Santicchia et al., 2018). This case illustrates how the diversity of 57 2019).

contexts animals can face could be key in maintaining the enormous variation in behavioural traits documented (Nettle, 2006; Briffa \& Sneddon, 2016; Roche, Careau \& Binning, 2016).

Nevertheless, the contextual components of animal behavioural traits are poorly understood and remain an eminent subject of debate among scientists (Koski, 2014; Weiss, 2018; Wilson et al.,

Particularly relevant are the fitness consequences of behavioural traits that affect mortality. With predators being among the most frequent causes of mortality in many animals (Lima, 2002; Beauchamp, Wahl \& Johnson, 2007), the substantial effect of antipredator behaviour on prey fitness comes as no surprise (Lind \& Cresswell, 2005). Prey's behavioural traits are tuned to, and affected by, predation pressure in intricate ways (Toscano \& Griffen, 2014; Belgrad \& Griffen, 2016). On the one hand, predators may trigger plastic behavioural responses in their prey (Quinn \& Cresswell, 2005; Dingemanse et al., 2010). For instance, Euricea nana salamanders reduce their activity time in the presence of predators (Davis \& Gabor, 2015). Likewise, Parus major tits exposed to predators have a lower tendency to explore than non-exposed controls (Abbey-Lee, Mathot \& Dingemanse, 2016), and juvenile Negaprion brevirostris sharks that exhibit more exploratory behaviour forage in riskier habitats, but only under low predation pressure (Dhellemmes et al., 2021). On the other hand, the relationships between predation risk and behavioural traits may transcend plasticity, as behaviour can be persistent across environments (Dosmann \& Mateo, 2016). In such a scenario, the ways in which behaviour affects predation risk can be complex. For example, shy Rutilus rutilus roaches are more likely to be preyed on by ambushing predators than bold conspecifics (Blake et al., 2018), 
74 whereas bolder Panopeus herbstii crabs experience greater mortality rates (Belgrad \& Griffen, 75 2018).

76 Despite the fact that some trends have been detected, inter-individual variation in 77 antipredator behavioural traits is oftentimes high (López et al., 2005; Brown et al., 2014;

78 Cremona et al., 2015). Such variation could be maintained by spatial differences in predation 79 pressure driving diverging behavioural traits. Supporting this possibility, Phoxinus phoxinus 80 minnows from a population under greater predation pressure are bolder but less active than 81 conspecifics from a population where predators are less abundant (Kortet et al., 2015). Indeed, 82 how animals make use of space affects their success against predators (Leblond, Dussault \& 83 Ouellet, 2013). Moreover, whenever the sexes are subjected to differential predation pressures, 84 sexual disparities in behaviour could be expected. For instance, highly active Perca fluviatilis 85 perch males face greater mortality than females (Yli-Renko, Pettay \& Vesakoski, 2018), and 86 Poecilia reticulata guppy males are significantly bolder than females (Harris et al., 2010). The protection lent by antipredator defences of different kinds could buffer the effects of predation on behavioural traits. Other potential sources of variation in antipredator behaviour, however, remain underexplored - such as locomotion, chemical deterrents, and colour. One of the most widespread antipredator defences is locomotion, as an active flight can be efficient in avoiding predators (Watkins, 1996; McGee et al., 2009). Although locomotion has a behavioural component, as animals tune their investment on locomotion according to the benefits it can yield in different situations (Zamora-Camacho, García-Astilleros \& Aragón, 2018), it may also

94 function as a capability that is dependent on traits other than behaviour (Zamora-Camacho, 2018). Other antipredator defences are neatly non-behavioural and passive. Such is the case with 
97 2001; Brodie, 2009; Savitzky et al., 2012). Aposematic coloration (i.e., conspicuous colours and

98 patterns that potential predators associate with unpalatability and actively avoid) can be

99 frequently found alongside chemical deterrents(Saporito et al., 2007; Zvereva \& Kozlov, 2016;

100 Ruxton et al., 2018), thus providing their carriers with additional defence from predators

101 (Skelhorn \& Rowe, 2006; Prudic, Skemp \& Papaj, 2007). However, the potential link between

102 these antipredator strategies and behavioural traits requires further exploration.

103 The relationship between body size and predation is particularly interesting. On the one

104 hand, larger prey could be easier to detect (Mänd, Tammaru \& Mappes, 2007; Karpestam,

105 Merilaita \& Forsman, 2014), while, on the other hand, larger prey can be more difficult to

106 handle (Díaz \& Carrascal, 1993; Kalinkat et al., 2013). In fact, survivorship of Hyla

107 chrysoscelis tadpoles to attacks by Tramea lacerata dragonfly nymphaea increases with body

108 size (Semlitsch, 1990). Larger grasshoppers are also better defended against a wide array of

109 predators (Whitman \& Vincent, 2008). However, larger predators do not necessarily prefer larger

110 prey (Tsai, Hsieh \& Nakazawa, 2016), although they can exploit prey of a wider size range

111 (Radloff \& du Toit, 2004). The influence of the morphology of a predator's mouthparts is also

112 important, with gape-limited predators preferring smaller prey, while gape-unconstrained

113 predators are less dependent on their prey's body size (Jobe, Montaña \& Schalk, 2019).

114 Furthermore, the role of prey body size may depend on other antipredator strategies. For

115 example, whereas detectability of cryptic prey can appear unrelated to body size, conspicuous

116 prey might be more detectable at larger body sizes (Mänd et al., 2007). Moreover, toxins are

117 more efficient antipredator defences in smaller prey (Smith, Halpin \& Rowe, 2016).

118 Consequently, antipredator behaviour is not independent from body size, but such relationships

119 are intricate (Preisser \& Orrock, 2012).

Peer] reviewing PDF | (2021:12:69078:2:0:NEW 31 Jan 2022) 
In this work, I studied activity, exploratory behaviour, and boldness in the natterjack toad,

121 Epidalea calamita. Specifically, I tested whether these traits co-vary with other antipredator

122 strategies, including locomotion. This toad is cursorial, and uses quick runs to flee from its

123 predators (Zamora-Camacho, 2018). I also examined the potential effects of body size on these

124 behavioural traits. Additionally, this species has notable parotoid glands, which are a pair of

125 swollen structures located dorsally behind the eyes in many amphibian species. The size of these

126 glands is directly proportional to the quantity of chemical deterrents they are capable of ejecting

127 (Zechmeister, 1948; Llewelyn et al., 2012). The parotoid glands of E. calamita are aposematic,

128 with predators avoiding plasticine models with highly colour-contrasting parotoid glands

129 (Zamora-Camacho, 2021). I tested whether the aforementioned traits are correlated with sprint

130 speed and parotoid gland area and colour contrast. In addition, predation pressure is subject to

131 spatial variation, according to an experiment where plasticine toad models received more attacks

132 in an agrosystem than in a natural habitat (Zamora-Camacho, 2021). Agrosystem toads are larger

133 than those from a natural habitat (Zamora-Camacho \& Comas, 2017), which could be an

134 adaptive response to greater predator pressure. Accordingly, I tested whether the aforementioned

135 traits vary between these habitats. Finally, the fact that males in this species are faster (Zamora-

136 Camacho, 2018) and have larger parotoid glands than females (Zamora-Camacho, 2021)

137 supports the notion that malesare under greater predation pressure than females, which aligns

138 with reports from other related species (e.g., Frétey et al., 2004). I tested whether the

139 aforementioned traits vary between sexes. I predict that individuals that are better suited against

140 predators (i.e., those that are faster, larger in body size, or have larger and more contrasting

141 parotoid glands) will display riskier behavioural traits, including being more active, bolder, and 
142 more exploratory. Similarly, I expect pine grove toads and females to be more active, bolder, and

143 more exploratory, as they are under reduced predation pressure.

144

145

146 Materials \& Methods

147 Study species

148

149

150

151

152

153

154

155

156

157

158

159

160

161

162

163

164 165

Epidalea calamita is a bufonid toad that thrives in diverse habitats, including unaltered as well as human-modified systems, in extensive areas in central and western Europe (Gomez-Mestre, 2014). Owing to the variable climatic conditions throughout this vast area, the phenology of this species is asynchronous, with aestivation being common in hot regions and hibernation occurring in cold climates (Gomez-Mestre, 2014). This species is primarily nocturnal, and its activity and reproduction take place during wet and not excessively cold weather, which happens during winters in warmer regions and in the spring in colder regions (Gomez-Mestre, 2014). Under adverse circumstances, they rest under rocks or logs, or in dens they burrow in loose soils, safe from predators (Gomez-Mestre, 2014). These toads are potential prey of a wide array of predators, including snakes (e.g., Natrix maura and Natrix astreptophora), birds (e.g. Larus ridibundus and Pica pica) and mammals (e.g., Meles meles), among others (see Gomez-Mestre, 2014). When under attack, toads use intermittent runs to flee (Zamora-Camacho, 2018). When escape is not possible, however, they commonly arch their loins and exhibit their parotoid glands, which can release great amounts of toxins (Stawikowski \& Lüddecke, 2019).

\section{Animal capture and management}

Toads were captured in the pine grove "Pinares de Cartaya" (SW Spain: 37²0' N, $7^{\circ} 09^{\prime}$ W) and in the agrosystem nearby. The forest is an 11000 -ha extension dominated by Pinus pinea and an 
166 undergrowth of Mediterranean bushes such as Pistacea lentiscus, Cistus ladanifer and

167 Rosmarinus officinalis. Although this plant assemblage could be considered autochthonous or

168 introduced in this region, its predominance dates back at least 4000 years (Martinez \& Montero,

169 2004), and as such it is deemed a natural habitat for the purposes of this study. The agrosystem is

170 about $5 \mathrm{~km}$ away from the pine grove, and is a 2800 -ha agricultural area where extensive

171 vegetable crops have gradually given way to intensive orange tree, blueberry, and strawberry

172 fields (among others) throughout the last few decades. In these croplands, landowners apply

173 fertilizers, fungicides, herbicides, and pesticides at their discretion, and artificial watering softens

174 the three-to-four-month-long summer droughts. Animal capture and management was according

175 to permits by the Junta de Andalucía government (Reference AWG/mgd GB-369-20).

176 Due to the mild local climate, E. calamita breeds in the winter there. Accordingly, toad

177 capture was conducted from December 2018 to March 2019. I caught 22 females and 20 males in

178 the agrosystem, plus 21 females and 25 males in the pine grove. Toads were captured by hand

179 while active in nights of suitable weather, then transported to the laboratory in plastic buckets

180 with well-ventilated lids and a substrate of humid earth. When they were in the laboratory, I used

181 their sexual dimorphism in coloration (females have browner backs and greyish throats, whereas

182 males have greener backs and purplish or pinkish throats; Zamora-Camacho \& Comas, 2019)

183 and the presence of blackish nuptial pads on male forelimbs (Gomez-Mestre, 2014), to sex them.

184 Next, I allocated them to individual plastic terraria $(20 \times 13 \times 9 \mathrm{~cm})$ with wet peat as a substrate

185 and an opaque plastic shelter. Toads were undisturbed in these terraria at all times, except during

186 the trials. Photos were taken approximately 24 hours after capture (see below). Then, 24 hours

187 after the photos, toad activity trials were recorded (see below). Finally, 24 hours after the activity 
188 trials, sprint speed tests were performed (see below). Toads were released at their capture sites 189 shortly afterward.

190

191 Measurements of coloration and morphology

192 I used a ruler to measure toad snout-vent length (hereafter, SVL) to the nearest mm, and a scale 193 (model CDS-100) to weigh them to the nearest $0.01 \mathrm{~g}$. No later than 24 hours after capture, I 194 orthogonally photographed each toad's back using a photo camera Canon EOS 550D, set at 18 195 megapixels of resolution, F10 of shutter-aperture, and a focal length fixed at $53 \mathrm{~mm}$. Only 196 exposure time was allowed to be automatically adjusted by the device, to optimize sharpness in 197 each individual photo. The camera was secured to a tripod, which guaranteed perpendicularity, 198 steadiness, and a constant distance of $40 \mathrm{~cm}$ from the lens to the photographed area. This area 199 was a square (30 $\mathrm{cm}$ side), white piece of paper that lay horizontal. On both lateral and the rear 200 sides (considering that the tripod was located opposite to the front side), three square $(30 \mathrm{~cm}$ 201 side), white pieces of white polyester sat vertically, conforming an incomplete cube which 202 lacked the front (allowing toad handling) and the upper sides (allowing photograph taking). In 203 order to avoid all parasitic lights (i.e., any uncontrolled source of light), photos were taken at 204 night in a completely closed room, where the only sources of light were two 80W white-light 205 bulbs, one next to each lateral side of the cube, externally to it, at a height of $20 \mathrm{~cm}$, so that 206 shades on the photographed area were prevented and the white polyester of the lateral, vertical 207 squares filtered the light. This setting is depicted in Fig. S1 in Supplementary Material. 208 Immediately prior to taking the photos, once the set was fixed as described, I calibrated white 209 balance to a spotless piece of paper, after which I added a standardized colour chart (IMAGE 210 Photographic) for digital calibration of white balance, and a piece of graph paper to calibrate 
211 length. Any remainder of humidity and dirt was gently removed from the toads' skins with a 212 disposable napkin before each photo.

213 Afterwards, these photos were processed with the software Adobe Photoshop CS5.

214 Firstly, I calibrated white balance one more time in each photo by using the tool eyedropper in

215 the white calibration function on the colour chart. Furthermore, colour mode was set to the

$216 \mathrm{~L} * \mathrm{a} * \mathrm{~b} *$ colour space preconized by the Commision Internationale d'Eclairage (CIE)

217 (Montgomerie, 2006). This is a three-dimensional colour space were L* quantifies lightness, and

218 varies from 0 (pure black) to 100 (pure white); $a^{*}$ quantifies the green-red axis (positive values

219 represent red and negative values represent green); and $b^{*}$ quantifies the blue-yellow axis

220 (positive values represent yellow and negative values represent blue). I calibrated length using

221 the piece of graph paper, and manually outlined both parotoid glands making use of the lasso

222 tool, which allowed me to calculate the sum of the areas of each. After this, parotoid gland

223 relative area was calculated as the residuals of regression of parotoid gland area against SVL.

224 Once the parotoid glands were outlined, I calculated their average colour and, with the histogram 225 tool, retrieved their average values of $\mathrm{L}^{*}, \mathrm{a}^{*}$, and $\mathrm{b}^{*}$. Lastly, I followed the same steps to trace 226 the dorsum (excluding the parotoid glands and the limbs) and retrieve its average $\mathrm{L}^{*}, \mathrm{a}^{*}$, and $\mathrm{b}^{*}$ 227 values. The average $L^{*}, a^{*}$, and $b^{*}$ parotoid gland and dorsum values were used to calculate 228 parotoid gland contrast $\left(\Delta \mathrm{E}^{*}\right)$ as in the CIE formula to assess difference in colour: $\Delta \mathrm{E}^{*}=\left(\Delta \mathrm{L}^{* 2}\right.$ $\left.229+\Delta \mathrm{a}^{* 2}+\Delta \mathrm{b}^{* 2}\right)^{1 / 2}$ (Nguyen, Nol \& Abraham, 2007; Moreno-Rueda et al., 2019).

\section{Measurements of activity and sprint speed}

232 Starting 24 hours after the photos were taken, toads were recorded for activity and sprint speed 233 trials (see details below), in this order. Videos were filmed with a camera Canon EOS 550D, at 
23425 frames per second. The camera was attached to a $2.5 \mathrm{~m}$ high tripod, with a $90^{\circ}$ angle, at all 235 times. In both trials, only one individual was recorded at a time. To remove the effect that 236 temperature may have on amphibian activity (Muller, Cade \& Schwarzkopf, 2018) and 237 locomotion (Preest \& Pough, 2003), the room was at approximately $19^{\circ} \mathrm{C}$ at all times. Light 238 conditions were standardized, as the only light source during all trials was a 60W white light 239 bulb $2.5 \mathrm{~m}$ high at the centre of the container where the toad was performing the trial in question 240 (see below). All videos were recorded at night (approximately between 21:00 and 02:00, local 241 time), when these toads are naturally active (Gomez-Mestre, 2014).

\section{Measurement of activity}

244 Activity trials were recorded while these toads were freely moving in a plastic arena $(54 \times 27 \times 40$ $245 \mathrm{~cm}$ ). A grid of $9 \mathrm{~cm}$ side squares was painted with non-toxic ink on the bottom of this arena.

246 Prior to the recordings, toads were placed at the centre of the arena, enclosed within a vertical 247 hollow cylinder (50 cm high, $15 \mathrm{~cm}$ diameter) open at its lower end. The cylinder was built with 248 a metal mesh (5 mm light), which allowed acclimation to the experimental setting. After two 249 minutes, the cylinder was gently removed in the vertical plane, and the toad's activity was 250 recorded for 10 minutes (Chajma, Kopecký \& Vojar, 2020).

251 Videos were then analysed with the program Tracker v. 4.92. I measured several 252 variables as surrogates of different traits of alleged relevance in the behaviour of animals in 253 general (Réale et al., 2007) and of amphibians in particular (Kelleher, Silla \& Byrne, 2018).

254 Activity time was the amount of time (s) the toad spent moving (Chajma et al., 2020).

255 Exploration behaviour was estimated as the number of squares visited (excluding squares that 256 had been visited before; Chajma et al., 2020) and the number of square visits (counting the 
257 number of times any square was visited, including repeated visits; Carlson \& Langkilde, 2013).

258 These measures differ in the fact that the former assumes that the individual distinguishes and

259 keeps track of the areas that have already been visited, whereas the latter assumes the opposite 260 (Carlson \& Langkilde, 2013). Time until the first move (i.e., latency) was also recorded, as a 261 surrogate of the shyness/boldness gradient, as bolder individuals are expected to start moving 262 sooner (Chajma et al., 2020). The use of space is also widely considered a surrogate of the 263 shyness/boldness gradient, in amphibians (Réale et al., 2007; Carlson \& Langkilde, 2013; 264 Chajma et al., 2020) and other taxa (Burns, 2008; Harris, D'Eath \& Healy, 2009). Specifically, 265 thigmotaxis, the tendency for some individuals to remain in the periphery of their enclosures 266 next to the walls rather than in the open areas, has been regarded as an anxiety-like, predator267 avoidance behaviour as opposed to the boldness subjacent to the use of open areas (Harris et al., 268 2009; Carlson \& Langkilde 2013; Chajma et al., 2020). Therefore, I also estimated the 269 shyness/boldness gradient by counting independently the number of external and internal squares 270 visited (excluding squares that had been visited before) and the number of external and internal 271 square visits (counting the number of times squares of these types were visited, including 272 repeated visits). Then, I divided the number of external squares visited by the total number of 273 squares visited (external squares visited ratio), as well as the number of external square visits by 274 the total number of square visits (external square visit ratio). Both ratios have a direct 275 relationship with boldness. These measurements are relevant in an ecological context, as 276 laboratory surrogates of animal behaviour mirror actual behaviour in the wild (Herborn et al., 277 2010). 278

\section{Measurement of sprint speed}


280 Prior to conducting and recording thesprint speed trials, I emptied toad bladders by firmly - but 281 gently - pressing their lower abdomens, which eliminates any potential effect of different bladder 282 water burden by reducing it to zero (Preest \& Pough, 1989; Walvoord, 2003; Prates et al., 283 2013). Next, I allowed toads to rest in their terraria for one hour. After that, they were recorded 284 (with the same camera already described) while running along a brownish cardboard linear 285 raceway $(200 \times 15 \times 15 \mathrm{~cm})$. On its bottom, one transversal white stripe of insulating tape was 286 placed every $10 \mathrm{~cm}$, so that the raceway was longitudinally divided into 10 -cm stretches 287 delimited by contrasting-colour stripes easy to visualize in the videos. Locomotor performance 288 may depend on the substrate where the race takes place (Vanhooydonck et al., 2015): cardboard 289 provided a surface rough enough to facilitate an appropriate traction. I also set a dark background 290 at one end of the raceway, which could be viewed as a shelter and encourage toads' moving 291 forward (Zamora-Camacho, 2018; González-Morales et al., 2021). Individuals were placed at 292 the opposite end of the raceway, and continuously pursued as a way of encouraging running, 293 until they covered the raceway. Once these trials were completed, toads were released at their 294 capture sites within 24 hours. No visible damage was inflicted on toads because of this 295 investigation.

296 The footages produced were analysed with the program Tracker v. 4.92, which allows 297 frame-by-frame video handling. For each toad, I registered the time (to the nearest $0.01 \mathrm{~s}$ ) needed 298 to cover each stretch in the raceway, which equals the time elapsed between the moments when 299 the snout of a toad surpassed two consecutive white stripes (Martín \& López, 2001; Zamora300 Camacho et al., 2014; Zamora-Camacho, 2018). As the distance covered was $10 \mathrm{~cm}$ in all cases, 301 I calculated the speed (in $\mathrm{cm} / \mathrm{s}$ ) reached in each stretch by dividing $10 \mathrm{~cm}$ by the time (s) it took 
302 for the toad to cover it. I considered each individual's sprint speed as its highest speed value.

303 Finally, relative speed was calculated as the residuals of regression of sprint speed against SVL.

304

\section{Statistics}

306 Firstly, I built two correlation matrices, one including the behavioural traits measured (number of

307 squares visited, number of square visits, external squares visited ratio, external square visits 308 ratio, activity time, and time until the first move) and another including the antipredator defences 309 measured (body mass, parotoid gland contrast, parotoid gland relative area, and relative sprint 310 speed). The aim of these matrices was to detect collinearity between both sets of data. Most

311 behavioural traits measured were highly correlated, except for time until the first move (Table S1

312 in Supplementary Material). On the contrary, the antipredator defences measured were mostly

313 uncorrelated, except for relative sprint speed and parotoid gland relative area, which were

314 positively and significantly correlated (Table S2 in Supplementary Material).

315 Then, to condense the correlated variables into fewer, uncorrelated variables, and solve

316 the limitation caused by the high collinearity among the variables measured, I conducted a

317 Principal Component Analysis (PCA; Jongman, Braak \& Tongeren, 1995) including the

318 behavioural traits measured that were correlated (number of squares visited, number of square

319 visits, external squares visited ratio, external square visits ratio, and activity time; Table S3a in

320 Supplementary Material) and another PCA including the antipredator defences measured that

321 were correlated (parotoid gland relative area and relative sprint speed; Table S3b in

322 Supplementary Material). In both cases, only Principal Components (PC) with an eigenvalue

323 greater than 1 were selected, according to the Guttmann-Kaiser Criterion (Yeomans \& Golder, 324 1982). 

were included as factors, and all PC with an eigenvalue greater than 1 in the second PCA

328

330 331

(namely, PC1, see Results below), as well as body mass and parotoid gland contrast, were included as covariates. The response variable of the first ANCOVA was time until the first move. In the second and the third ANCOVAs, the variable responses were each PC with an eigenvalue greater than 1 in the first PCA (namely, PCa and PCb, see Results below). Stepwise backward selection was applied to these ANCOVAs. Tests were conducted with the package "nlme" (Pinheiro et al., 2012) in the software R (R Development Core Team, 2012). Before conducting parametric statistical analyses, I checked that the data met the criteria of homoscedasticity and residual normality (Quinn \& Keough, 2002). Since no transformation could make body mass homoscedastic, I implemented the function "varIdent" (Zuur et al., 2009).

\section{Results}

\section{Variable grouping according to PCAs}

In the PCA including the behavioural traits, the only two PC with eigenvalues greater than 1, named $\mathrm{PCa}$ and $\mathrm{PCb}$, explained jointly $88.99 \%$ of the total variance. PCa was strongly and positively correlated with the number of squares visited, the number of square visits, and activity time, whereas its correlations with the external squares visited ratio and the external square visits ratio were strong and negative (Table 1). Therefore, PCa was positively correlated with exploration behaviour, activity, and boldness. In turn, PCb was negatively correlated with all behavioural traits measured (Table 1). Therefore, $\mathrm{PCb}$ was negatively correlated with exploration behaviour and activity, and positively correlated with boldness. 
In the PCA including parotoid gland relative area and relative sprint speed, the only PC

350 with an eigenvalue greater than 1 , named PC1, explained $68.20 \%$ of the total variance. PC1 was

351 strongly and positively correlated with relative sprint speed and relative parotoid gland area

352 (Table 2).

353

354 ANCOVAs

355 After stepwise backward selection was applied to the ANCOVA including PCa as the response 356 variable, sex had a significant effect, with PCa being greater in females than in males (Mean \pm

357 SE; females: $0.387 \pm 0.220$; males: $-0.349 \pm 0.300 ; X_{1,85}^{2}=3.910 ; P=0.048$; Fig. 1). Moreover, 358 body mass had a negative, significant relationship with $\mathrm{PCa}\left(X^{2}{ }_{1,85}=8.122 ; \beta=-0.045 ; P=\right.$ 359 0.004).

360 After stepwise backward selection was applied to the two ANCOVAs including either

$361 \mathrm{PCb}$ or time until the first move as response variables, no factor or covariate appeared significant 362 in either case.

363

\section{Discussion}

365 My findings show that the antipredator defences of E. calamita are linked to behaviour in some 366 cases, but not in others. For example, relative speed as well as parotoid gland contrast and size

367 were not related to the traits studied. In contrast with other bufonids, such as Rhinella marina, 368 whose jumping distance is directly proportional to body length (Hudson et al., 2020), sprint 369 speed of E. calamita is unrelated to body size (Zamora-Camacho, 2018), which allows for a 370 separate evaluation of both parameters. The absence of correlations between speed and the 371 behavioural traits tested as a part of this study is aligned with findings on Zootoca vivipara (Le 372 Galliard et al., 2013) and Phrinocephalus vlangalii lizards (Chen et al., 2019), but not with 
373 findings on Myotomis unisulcatus (Agnani et al., 2020) and Tamias striatus rodents (Newar \&

374 Careau, 2018). It is worth mentioning that all toads in this sample engaged in flight behaviour.

375 However, the tonic immobility observed in other cases, especially in taxa that rely on their toxins

376 against attacks, can also be considered an expression of boldness (Edelaar et al., 2012; Hudson,

377 Brown \& Shine, 2017). In turn, relationships between overall coloration and different

378 behavioural traits have been described in taxa as disparate as tortoises (Mafli, Wakamatsu \&

379 Roulin, 2011), fish (Schweitzer, Motreuil \& Dechaume-Moncharmont, 2015) and birds

380 (Costanzo et al., 2018). However, there is a lack of such studies on amphibians (reviewed in

381 Kelleher et al., 2018) and, to the best of my knowledge, the potential relationship between

382 aposematism and behaviour at the individual level remains unexplored thus far. According to

383 these results, the degree of aposematism is unrelated to behaviour in these toads. A decoupling

384 between colour and behaviour, albeit in a reproductive context, has also been described in

385 phrysonomatid lizards (Wiens, 2000). These mismatches between some antipredator defences

386 and behaviour could suggest that the success of these traits is independent of each other, or

387 simply that they have evolved separately.

388 Similarly, parotoid gland size was not associated with a more exploratory and bolder

389 behaviour nor increased activity time. These are considered risky behavioural traits that increase

390 conspicuousness to predators (Hall et al., 2015; Reader, 2015). This finding does not support the

391 prediction that more extensive parotoid glands, capable of releasing greater amounts of toxins

392 (Zechmeister, 1948; Llewelyn et al., 2012), could better protect their bearers against predators,

393 thus reducing the potential costs of risky behaviours with regard to their benefits (Smith \&

394 Blumstein, 2008; Niemelä, Lattenkamp \& Dingemanse, 2015). However, the amount of toxin

395 contained in the glands at the moment of the trials could not be assessed. This could represent a 
396 limitation of the experimental design, as closely-related $R$. marina toads adjust their antipredator

397 behaviour after parotoid gland toxin depletion (Blennerhassett et al., 2019). On the contrary,

398 body mass was negatively related to exploratory behaviour, boldness, and activity time.

399 Although larger prey individuals could be better suited against gape-limited predators (Turesson, 400 Persson \& Brönmark, 2002; Urban, 2007), this is not necessarily true when predators are non401 gape-limited (Jobe et al., 2019; Stretz, Andersson \& Burkhart, 2019). Indeed, gape unconstrained 402 predators such as mammals (Owen-Smith \& Mills, 2008) or birds (Comay \& Dayan, 2018) can 403 and do handle remarkably voluminous prey. Although some local snakes (mainly Natrix 404 astreptophora and N. maura; Gomez-Mestre, 2014), which are gape-limited, have been described 405 as predators of these toads, their activity seldom overlap, as those snakes are mainly diurnal and 406 hibernate in the winter (Santos, 2015; Pleguezuelos, 2018), whereas E. calamita toads are 407 primarily active in winter nights (Gomez-Mestre, 2014). Therefore, the most likely predators of 408 E. calamita adults are birds and mammals (Gomez-Mestre, 2014), to which larger toads could be 409 more conspicuous, but not less vulnerable. In this context, the less risky behaviour of larger toads 410 could be advantageous against their main predators. Variation in the relative pressure exerted by 411 dissimilar predator preferences on body size might underlie the apparently contradictory 412 relationships between body size and behaviour found among this and other studies. For example, 413 whereas bold Lacerta monticola male lizards are smaller (López et al., 2005), there is a positive 414 relationship between body size and boldness in juvenile Tropidonophis mairii snakes (Mayer, 415 Shine \& Brown, 2016) and between body size and exploratory behaviour in Pseudophryne 416 corroboree frogs (Kelleher et al., 2017).

417 Moreover, females exhibited a bolder behaviour than males. This finding is aligned with 418 the assumption that female toads are under milder predation pressure (Frétey et al., 2004), and 
419 can thus afford riskier behaviours. E. calamita males in this system are faster (Zamora-Camacho, 420 2018), brighter (Zamora-Camacho \& Comas, 2019), and have larger parotoid glands than

421 females (Zamora-Camacho, 2021), which could be interpreted as antipredator defences triggered 422 by a harsher predation pressure. Remarkably, other toads, such as $R$. marina (Gruber et al., 423 2018) or Sclerophrys gutturalis (Baxter-Gilbert, Riley \& Measey, 2021) do not appear to differ in 424 these behavioural traits. Sexual differences in boldness, moreover, vary notably in other taxa: 425 male dogs (Starling et al., 2013) and Brachyraphis episcopi fish (Brown, Jones \& Braithwaite, 426 2007) are bolder than females, female Diomeda exulans albatross are bolder than males (Patrick, 427 Charmantier \& Weimerskirch, 2013), and Diploptera punctata male and female cockroaches do 428 not diverge in boldness (Stanley, Mettke-Hofmann \& Preziosi, 2017). Lastly, habitat did not affect the behavioural traits measured, despite the fact that this 430 species is under greater predation pressure in agrosystem than in pine grove (Zamora-Camacho, 2021). Other traits seem to be aligned with this spatial pattern of predation pressure: agrosystem toads have a more intermittent locomotion mode (Zamora-Camacho, 2018), are brighter (Zamora-Camacho \& Comas, 2019), and have larger and more contrasting parotoid glands than pine grove conspecifics (Zamora-Camacho, 2021), which could signify greater antipredator defences, likely triggered by more intense predation pressure. Remarkably, while habitat alone does not innately affect boldness behaviour of S. gutturalis tadpoles (Mühlenhaupt et al., 2022), predation pressure can explain spatial divergence in behavioural and morphological traits of other anurans, such as Bombina variegata toads (Kang et al., 2017). Spatial differences in 439 boldness may have implications at other levels.

\section{Conclusions}


443 To conclude, relative speed as well as parotoid gland contrast and size appeared unrelated to the

444 behavioural traits studied. In turn, body mass was negatively related to activity time, boldness

445 and exploration. This trend is consistent with the fact that most predators of this species are gape

446 unconstrained and could more easily find and hunt larger toads. Females were bolder, which

447 matches the assumptions that males and agrosystem toads are under harsher predation pressure.

448 Nonetheless, the behavioural traits measured did not vary between habitats, which is not aligned

449 with previous findings that agrosystem toads are under greater predation pressure. Jointly, these

450 results partly support the predictions that behaviour is tuned to antipredator defences and to

451 differential predation pressure in this toad. In the light of these results, disentangling the potential

452 links between behaviour and antipredator defences, so far underexplored, could be key in the

453 understanding of predator avoidance.

454

455 Acknowledgements

456 Gregorio Moreno-Rueda and Mar Comas kindly provided their logistic support. Comments by 457 James Baxter-Gilbert, Max Mühlenhaupt, Cameron Hudson and an anonymous reviewer improved 458 the manuscript.

\section{References}

460 Abbey-Lee RN, Mathot KJ, Dingemanse N (2016) Behavioral and morphological responses to 461 perceived predation risk: a field experiment in passerines. Behav Ecol 27:857-864.

462 Agnani P, Thomson J, Schradin C, Careau V (2020) The fast and the curious II: performance, 463 personality, and metabolism in Karoo bush rats. Behav Ecol Sociobiol 74:123.

464 Baxter-Gilbert J, Riley JL, Measey J (2021) Fortune favors the bold toad: urban-derived behavioral 465 traits may provide advantages for invasive amphibian populations. Behav Ecol Sociobiol 75: 130. 
467 Beauchamp DA, Wahl D, Johnson BM (2007) Predator-prey interactions. In: Guy CS, Brown MJ, 468 editors. Analysis and interpretation of inland fisheries data. Bethesda, MD: American $469 \quad$ Fisheries Society. p. 765-842.

470 Belgrad BA, Griffen BD (2016) Predator-prey interactions mediated by prey personality and $471 \quad$ predator hunting mode. Proc R Soc B 283:20160408.

472 Biro PA, Stamps JA (2008) Are animal personality traits linked to life-history productivity? Trend $473 \quad$ Ecol Evol 23:361-368.

474 Blake CA, Andersson ML, Hulthén K, Nilsson PA, Brönmark C (2018) Conspecific boldness and 475 predator species determine predation-risk consequences of prey personality. Behav Ecol 476 Sociobiol 72:133.

477 478

479

480

481

482

483

484 485 486 487 488 489

Blennerhassett RA, Bell-Anderson K, Shine R, Brown GP (2019) The cost of chemical defence: the impact of toxin depletion on growth and behaviour of cane toads (Rhinella marina). Proc R Soc B 286:20190867.

Briffa M, Sneddon LU (2016) Proximate mechanisms of among-individual behavioural variation in animals. Behaviour 153:1509-1515.

Briffa M, Sneddon LU, Wilson AJ (2015) Animal personality as a cause and consequence of contest behaviour. Biol Lett 11:20141007.

Brodie ED III (2009) Toxins and venoms. Curr Biol 19:R931-R935.

Brown C, Jones F, Braithwaite WA (2007) Correlation between boldness and body mass in natural populations of the poecilid (Brachyraphis episcopi). J Fish Biol 71:1590-1601.

Brown GE, Elvidge CK, Ramnarine I, Chivers DP, Ferrari MCO (2014) Personality and the response to predation risk: effects of information quantity and quality. Anim Cogn 17:1063-1069. 
490 Burns JG (2008) The validity of three tests of temperament in guppies (Poecilia reticulata). J $491 \quad$ Comp Psychol 122:344-356.

492 Carlson BE, Langkilde T (2013) Personality traits are expressed in bullfrog tadpoles during open493 field trials. J Herpetol 47:378-383.

494 Chajma P, Kopecký O, Vojar J (2020) Individual consistency in exploration and shyness but not 495 496 activity in smooth newts (Lissotriton vulgaris): the effect of habituation? J Zool 311:269276.

497 498

499

500

501

502

503

504

505

506

507 508

509

510

511 metabolic/performance traits in an Asian agamid lizard (Phrynocephalus vlangalii). PeerJ 7:e7205.

Comay O, Dayan T (2018) What determines prey selection in owls? Roles of prey traits, prey class, environmental variables, and taxonomic specialization. Ecol Evol 8:3382-3392.

Costanzo A, Romano A, Ambrosini R, Parolini M, Bubolini D, Caprioli M, Corti M, Canova L, Saino N (2018) Barn swallow antipredator behavior covaries with melanic coloration and predicts survival. Behav Ecol 29:1472-1480.

Cremona T, Mella VSA, Webb JK, Crowther MS (2015) Do individual differences in behavior influence wild rodents more than predation risk? J Mammal 96:1337-1343.

Davis DR, Gabor CR (2015) Behavioral and physiological antipredator responses of the San Marcos salamander, Eurycea nana. Physiol Behav 139:145-149.

Dhellemmes F, Smukall MJ, Guttridge TL, Krause J, Hussey NE (2021) Predator abundance drives the association between exploratory personality and foraging habitat risk in a wild marine meso-predator. Funct Ecol 35:1972-7984. 
512 Díaz JA, Carrascal LM (1993) Variation in the effect of profitability on prey size selection by the 513 lacertid lizard Psammodromus algirus. Oecologia 94:23-29.

514 Dingemanse NJ, Kazem AJN, Réale D, Wrigth J (2010) Behavioural reaction norms: animal 515 personality meets individual plasticity. Trend Ecol Evol 25:81-89.

516 Dingemanse NJ, Réale D (2005) Natural selection and animal personality. Behaviour 142:1165$517 \quad 1190$.

518 Dosmann A, Mateo JM (2014) Food, sex and predators: animal personality persists with 519 multidimensional plasticity across complex environments. Anim Behav 90:109-116.

520 Dugatkin LA (2020) Principles of animal behavior. University of Chicago Press.

521 Edelaar P, Serrano D, Carrete M, Blas J, Potti J, Tella JL (2012) Tonic immobility is a measure of 522 boldness toward predators: an application of Bayesian structural equation modeling. Behav 523 Ecol 23:619-626.

524 Frétey T, Cam E, Le Garff B, Monnat JY (2004) Adult survival and temporary emigration in the 525 common toad. Can J Zool 82:859-872.

526

527

528

529

530

531

532

533

534

Gomez-Mestre I (2014) Sapo corredor - Epidalea calamita (Laurenti, 1768). In: Salvador A, Marco A, editors. Enciclopedia Virtual de los Vertebrados Españoles. Museo Nacional de Ciencias Naturales, Madrid. See http://www.vertebradosibericos.org

González-Morales JC, Rivera-Rea J, Moreno-Rueda G, Bastiaans E, Castro-López M, Fajardo V (2021) Fast and dark: the case of Mezquite lizards at extreme altitude. J Therm Biol 102:103115.

Gruber J, Brown G, Whiting MJ, Shine R (2018) Behavioural divergence during biological invasions: a study of cane toads (Rhinella marina) from contrasting environments in Hawai'i. R Soc Open Sci 5:180197. 
535 Hall ML, van Asten T, Katsis AC, Dingemanse NJ, Magrath MJL, Mulder RA (2015) Animal 536 personality and pace-of-life syndromes: do fast-exploring fairy-wrens die young? Front $537 \quad$ Ecol Evol 3:28.

538 Harris AP, D'Eath RB, Healy SD (2009) Environmental enrichment enhances spatial cognition in 539 rats by reducing thigmotaxis (wall hugging) during testing. Anim Behav 77:1459-1464.

540 Harris S, Ramnarine IW, Smith HG, Pettersson LB (2010) Picking personalities apart: estimating 541 the influence of predation, sex and body size on boldness in the guppy Poecilia reticulata. $542 \quad$ Oikos 119:1711-1718.

543 Herborn KA, Macleod R, Miles WTS, Schofield ANB, Alexander L, Arnold KE (2010) 544 Personality in captivity reflects personality in the wild. Anim Behav 79:835-843.

545 Hudson CM, Brown GP, Shine R (2017) Evolutionary shifts in anti-predator responses of invasive 546 cane toads (Rhinella marina). Behav Ecol Sociobiol 71:134.

547 Hudson CM, Vidal-García M, Murray TG, Shine R (2020) The accelerating anuran: evolution of 548 locomotor performance in cane toads (Rhinella marina) at an invasion front. Proc R Soc B $549 \quad 287: 20201964$.

550 Jobe KL, Montaña CG, Schalk CM (2019) Emergent patterns between salamander prey and their $551 \quad$ predators. Food Webs 21:e0128.

552 Jongman RHG, Braak CJF, Tongeren OFR (1995) Data analysis in community and landscape 553 ecology. Cambridge: Cambridge University Press.

554 Kalinkat G, Schneider FD, Digel C, Guill C, Rall BC, Brose U (2013) Body masses, functional 555 responses and predator-prey stability. Ecol Lett 16:1126-1134. 
556 Kang C, Sherratt TN, Kim YE, Shin Y, Moon J, Song U, Kang JY, Kim K, Jang Y (2017)

557 Differential predation drives the geographical divergence in multiple traits in aposematic 558 frogs. Behav Ecol 28:1122-1130.

559 Karpestam E, Merilaita S, Forsman A (2014) Body size influences differently the detectabilities 560 of colour morphs of cryptic prey. Biol J Linn Soc 113:112-122.

561 Kelleher SR, Silla AJ, Byrne PG (2018) Animal personality and behavioral syndromes in 562 amphibians: a review of the evidence, experimental approaches, and implications for conservation. Behav Ecol Sociobiol 72:79.

564 Kelleher SR, Silla AJ, Dingemanse NJ, Byrne PG (2017) Body size predicts between-individual 565 differences in exploration behaviour in the southern corroboree frog. Anim Behav 129:161566 170.

567

Kortet R, Sirkka I, Lai YT, Vainikka A, Kekäläinen J (2015) Personality differences in two minnow populations that differ in their parasitism and predation risk. Front Ecol Evol 3:9.

569

570

571

572

573

574

575

576

577 578

Koski SE (2014) Broader horizons for animal personality research. Front Ecol Evol 2:70.

Le Galliard JF, Paquet M, Cisel M, Montes-Poloni L (2013) Personality and the pace-of-life syndrome: variation and selection on exploration, metabolism and locomotor performances. Funct Ecol 27:136-144.

Leblond M, Dussault C, Ouellet JP (2013) Impacts of human disturbance on large prey species: do behavioral reactions translate to fitness consequences? PLoS ONE 8:e73695.

Lima SL (2002) Putting predators back into behavioral predator-prey interactions. Trend Ecol Evol 17:70-75.

Lind J, Cresswell W (2005) Determining the fitness consequences of antipredator behavior. Behav Ecol 16:945-956. 
579 Llewelyn J, Bell K, Schwarzkopf L, Alford RA, Shine R (2012) Ontogenetic shifts in a prey's $580 \quad$ chemical defences influence feeding responses of a snake predator. Oecologia 169:965581973.

582 López P, Hawlena D, Polo V, Amo L, Martín J (2005) Sources of individual shy-bold variations 583 in antipredator behaviour of male Iberian rock lizards. Anim Behav 69:1-9.

584 MacPherson B, Mashayekhi M, Gras R, Scott R (2017) Exploring the connection between 585 emergent animal personality and fitness using a novel individual-based model and decision

586 tree approach. Ecol Inform 40:81-92.

587 Mafli A, Wakamatsu K, Roulin A (2011) Melanin-based coloration predicts aggressiveness and 588 boldness in captive eastern Hermann's tortoises. Anim Behav 81:859-863.

589 Mänd T, Tammaru T, Mappes J (2007) Size dependent predation risk in cryptic and conspicuous 590 insects. Evol Ecol 21:485.

591 Martín J, López P (2001) Hindlimb asymmetry reduces escape performance in the lizard 592 Psammodromus algirus. Physiol Biochem Zool 74:619-624.

593 Martínez F, Montero G (2004) The Pinus pinea L. woodlands along the coast of South-western 594 Spain: data for a new geobotanical interpretation. Plant Ecol 175:1-18.

595 Mayer M, Shine R, Brown GP (2016) Bigger babies are bolder: effects of body size on personality 596 of hatching snakes. Behaviour 153:313-323.

597 McGee MR, Julius ML, Vajda AM, Norris DO, Barber LB, Schoenfuss HL (2009) Predator 598 avoidance performance of larval fathead minnows (Pimephales promelas) following short599 term exposure to estrogen mixtures. Aquat Toxicol 91:355-361.

600 Mebs D (2001) Toxicity in animals. Trends in evolution? Toxicon 39:87-96. 
601 Montgomerie R (2006) Analyzing colors. In: Hill GE, McGraw KJ, editors. Bird Coloration 602 Volume I: mechanisms and measurements. Cambridge MA; Harvard University Press. p $60390-140$.

604 Moreno-Rueda G, González-Granda LG, Reguera S, Zamora-Camacho FJ, Melero E (2019) 605 Crypsis decreases with elevation in a lizard. Diversity 11:236.

606 Mühlenhaupt M, Baxter-Gilbert J, Makhubo BG, Riley JL, Measey J (2022) No evidence for 607 innate differences in tadpole behavior between natural, urbanized, and invasive $608 \quad$ populations. Behav Ecol Sociobiol 76:11.

609 Muller BJ, Cade BS, Schwarzkopf L (2018) Effects of environmental variables on invasive 610 amphibian activity: using model selection on quantiles for counts. Ecosphere 9:e02067.

611 Nettle D (2006) The evolution of personality variation in humans and other animals. Am Psychol 612 61:622-631.

613 Newar SL, Careau V (2018) The fast and the curious: locomotor performance and exploratory 614 behaviour in eastern chipmunks. Behav Ecol Sociobiol 72:27.

615 Nguyen LP, Nol E, Abraham KF (2007) Using digital photographs to evaluate the effectiveness 616 of plover egg crypsis. J Wildl Manage 71:2084-2089.

617 Niemelä PT, Lattenkamp EZ, Dingemanse NJ (2015) Personality-related survival and sampling 618 bias in wild cricket nymphs. Behav Ecol 26:936-946.

619 Owen-Smith N, Mills MGL (2008) Predator-prey size relationships in African large-mammal food 620 web. J Anim Ecol 77:173-183.

621 Patrick SC, Charmantier A, Weimerskirch H (2013) Differences in boldness are repeatable and 622 heritable in a long-lived marine predator. Ecol Evol 3:4291-4299. 
623 Pinheiro J, Bates D, DebRoy S, Sarkar D, R Development Core Team (2012) nlme: linear and 624 nonlinear mixed effects models. R package version 3.1-103. Vienna: R Foundation for 625 Statistical Computing.

626 Pleguezuelos JM (2018) Culebra de collar mediterránea - Natrix astreptophora. In: Sanz JJ, 627 Martínez-Freiría F., editors. Enciclopedia Virtual de los Vertebrados Españoles. Museo Nacional de Ciencias Naturales, Madrid. See http://www.vertebradosibericos.org

629

630

631

632

633

634

635

636

637

638

639

640

641

642 Quinn JL, Cresswell W (2005) Personality, anti-predation behaviour and behavioural plasticity in 643

644 R Development Core Team (2012) R: a language and environment for statistical computing. 645

Prates I, Angilleta MJ, Wilson RS, Niehaus AC, Navas CA (2013) Dehydration hardly slows hopping toads (Rhinella granulosa) from xeric and mesic environments. Physiol Biochem Zool 86:451-457.

Preest MR, Pough FH (1989) Interaction of temperature and hydration on locomotion of toads. Funct Ecol 3:693-699.

Preest MR, Pough FH (2003) Effects of body temperature and hydration state on organismal performance of toads, Bufo americanus. Physiol Biochem Zool 76:229-239.

Preisser EL, Orrock JL (2012) The allometry of fear: interspecific relationships between body size and response to predation risk. Ecosphere 3:77.

Prudic KL, Skemp AK, Papaj DR (2007) Aposematic coloration, luminance contrast, and the benefits of conspicuousness. Behav Ecol 18:41-46.

Quinn GP, Keough MJ (2002) Experimental design and data analysis for biologists. Cambridge: Cambridge University Press. the chaffinch Fringilla coelebs. Behaviour 142:1377-1402. Vienna: R Foundation for Statistical Computing. 
646 Radloff FGT, du Toit JT (2004) Large predators and their prey in a southern African savanna: a 647 predator's size determines its prey size range. J Anim Ecol 73:410-423.

648 Reader SM (2015) Causes of individual differences in animal exploration and search. Topics Cogn. $649 \quad$ Sci 7:451-468.

650 Réale D, Reader SM, Sol D, McDougall PT, Dingemanse NJ (2007) Integrating animal 651 temperament within ecology and evolution. Biol Rev 82:291-318.

652 Roche DG, Careau V, Binning SA (2016) Demystifying animal 'personality' (or not): why 653 individual variation matters to experimental biologists. J Exp Biol 219:3832-3843.

654 Ruxton GD, Allen WL, Sherratt TN, Speed MP (2018) Avoiding attack: the evolutionary ecology 655 of crypsis, aposematism, and mimicry. New York: Oxford University Press.

656 Santicchia F, Gagnaison C, Bisi F, Martinoli A, Matthysen E, Bertolino S, Wauters LA (2018) 657 Habitat-dependent effects of personality on survival and reproduction in red squirrels. $658 \quad$ Behav Ecol Sociobiol 72:134.

659 Santos X (2015) Culebra viperine - Natrix maura. In: Salvador A, Marco A, editors. Enciclopedia 660 Virtual de los Vertebrados Españoles. Museo Nacional de Ciencias Naturales, Madrid. See 661 http://www.vertebradosibericos.org

662 663 664 665 666 667
Saporito RA, Zuercher R, Roberts M, Gerow KG, Donnelly MA (2007) Experimental evidence for aposematism in the Dendrobatid poison frog Oophaga pumilio. Copeia 2007:10061011.

Savitzky AH, Mori A, Hutchinson DA, Saporito RA, Burghardt GM, Lillywhite HB, Meinwald J (2012) Sequestered defensive toxins in tetrapod vertebrates: Principles, patterns, and prospects for future studies. Chemoecology 22:141-158. 
668 Schuett W, Tregenza T, Dall SRX (2010) Sexual selection and animal personality. Biol Rev $669 \quad 85: 217-246$.

670 Schweitzer C, Motreuil S, Dechaume-Moncharmont FX (2015) Coloration reflects behavioural 671 types in the convict cichlid, Amatitlania siquia. Anim Behav 105:201-209.

672 Semlitsch RD (1990) Effects of body size, sibship, and tail injury on the susceptibility of tadpoles 673 to dragonfly predation. Can J Zool 68:1027-1030.

674 Skelhorn J, Rowe C (2006) Avian predators taste-reject aposematic prey on the basis of their 675 chemical defence. Biol Lett 2:348-350.

676 Smith BR, Blumstein DT (2008) Fitness consequences of personality: a meta-analysis. Behav Ecol 677 19:448-455.

678 Smith KE, Halpin CG, Rowe C (2016) The benefits of being toxic to deter predators depends on 679 prey body size. Behav Ecol 27:1650-1655.

680 Stamps JA (2007) Growth-mortality tradeoffs and 'personality traits' in animals. Ecol Lett 10:355681 363.

682 Stanley CR, Mettke-Hofmann C, Preziosi RF (2017) Personality in the cockroach Diploptera 683 punctata: evidence for stability across developmental stages despite age effects on

684 boldness. PLoS ONE 12:e0176564.

685

686

687

688

689 affect boldness in dogs. Vet J 197:868-872.

Stawikowski R, Lüddecke T (2019) Description of defensive postures of the natterjack toad Epidalea calamita (Laurenti 1768) and notes on the release of toxic secretions. Herpetol Notes 12:443-445. 
690 Stretz P, Andersson TL, Burkhart JJ (2019) Macroinvertebrate foraging on larval Ambystoma 691 maculatum across ontogeny. Copeia 107:244-249.

692 Toscano BJ, Griffen BD (2014) Trait-mediated functional responses: predator behavioural type 693 mediates prey consumption. J Anim Ecol 83:1469-1477.

694 Tsai CH, Hsieh C, Nakazawa T (2016) Predator-prey mass ratio revisited: does preference of 695 relative prey body size depend on individual predator size? Funct Ecol 30:1979-1987.

696 Turesson H, Persson A, Brönmark C (2002) Prey size selection in piscivorous pikeperch 697 (Stizostedion lucioperca) includes active prey choice. Ecol Freshw Fish 11:223-233.

698 Urban MC (2007) The growth-predation risk trade-off under a growing gape-limited predation $699 \quad$ threat. Ecology 88:2587-2597.

700 Vanhooydonck B, Measey J, Edwards S, Makhubo B, Tolley KA, Herrel A (2015) The effects of 701 substratum on locomotor performance in lacertid lizards. Biol J Linn Soc 115:869-881.

702 Walvoord ME (2003) Cricket frogs maintain body hydration and temperature near levels allowing 703 maximum jump performance. Physiol Biochem Zool 76:825-835.

704 Watkins TB (1996) Predator-mediated selection on burst swimming performance in tadpoles of 705 the Pacific tree frog, Pseudacris regilla. Physiol Zool 69:154-167.

706 Weiss A (2018) Personality traits: a view from the animal kingdom. J Pers 86:12-22.

707 Whitman DW, Vincent S (2008) Large size as an antipredator defense in an insect. J Orthoptera 708 Res 17:353-371.

709 Wiens JJ (2000) Decoupled evolution of display morphology and display behaviour in 710 phrysonomatid lizards. Biol J Linn Soc 70:597-612. 
711 Wilson V, Guenther A, Øverli Ø, Seltmann MW, Altschul D (2019) Future directions for 712 personality research: contributing new insights to the understanding of animal behavior. 713 Animals 9:240.

714 Yeomans KA, Golder PA (1982) The Guttman-Kaiser criterion as a predictor of the number of 715 common factors. Statistician 31:221-229.

716 Yli-Renko M, Pettay JE, Vesakoski O (2018) Sex and size matters: selection on personality in 717 natural prey-predator interactions. Behav Proc 148:20-26.

718 Zamora-Camacho FJ (2018) Locomotor performance in a running toad: roles of morphology, sex 719 and agrosystem versus natural habitat. Biol J Linn Soc 123:411-421.

720 Zamora-Camacho FJ (2021) Sex and habitat differences in size and coloration of an amphibian's 721 poison glands match differential predator pressures. Integr Zool in press.

722 Zamora-Camacho FJ, Comas M (2017) Greater reproductive investment, but shorter lifespan, in 723 agrosystem than in natural-habitat toads. PeerJ 5:e3791.

724 Zamora-Camacho FJ, Comas M (2019) Beyond sexual dimorphism and habitat boundaries: 725 coloration correlates with morphology, age, and locomotor performance in a toad. Evol 726 Biol 46:60-70.

727 Zamora-Camacho FJ, García-Astilleros J, Aragón, P (2018) Does predation risk outweigh the costs 728 of lost feeding opportunities or does it generate a behavioural trade-off? A case study with 729 Iberian ribbed newt larvae. Biol J Linn Soc 125:741-749. length, body mass, gender, gravidity, and elevation on escape speed in the lizard Psammodromus algirus. Evol Biol. 41:509-517.

733 Zechmeister L (1948) Progress in the Chemistry of Organic Natural Products. Springer. 
734 Zhao QS, Hu YB, Liu PF, Chen LJ, Sun YH (2016) Nest site choice: a potential pathway linking 735 personality and reproductive success. Anim Behav 118:97-103.

736 Zuur AF, Ieno EN, Walker NJ, Saveliev AA, Smith GM (2009) Mixed effects models and 737 extensions in ecology with R, Statistics for biology and health. Springer Science + Business 738 Media, LLC New York, USA.

739 Zvereva EL, Kozlov MV (2016) The costs and effectiveness of chemical defenses in herbivorous 740 insects: a meta-analysis. Ecol Monogr. 86:107-124.

741 
Figure 1

Sex and habitat differences in PCa.

PCa was greater in females than in males, but did not differ between habitats. Note that PCa was positively correlated with the number of squares visited, the number of square visits, and activity time, and negatively correlated with the external squares visited ratio and the external square visits ratio. Vertical bars represent standard errors. Sample sizes are indicated.

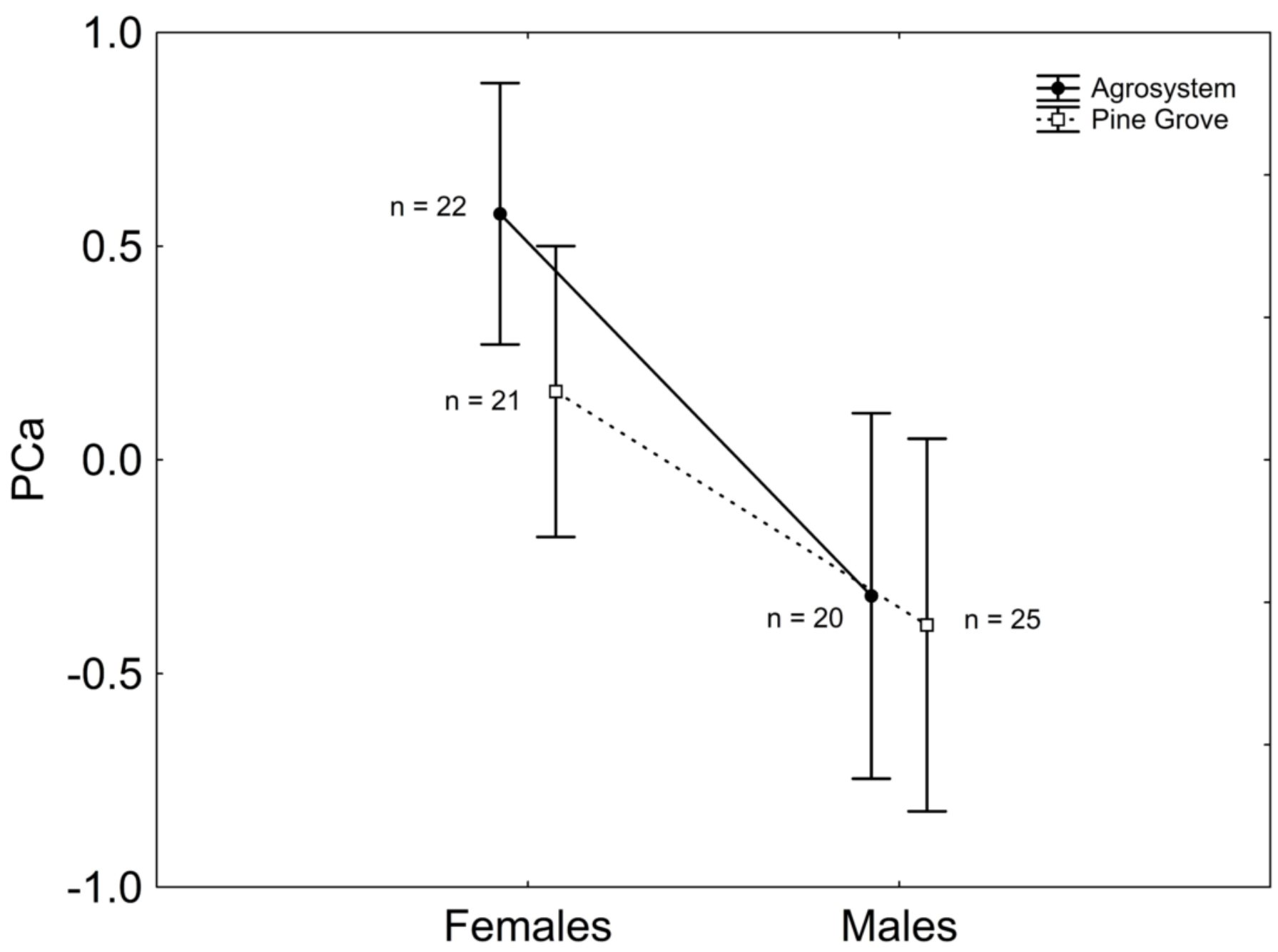




\section{Table $\mathbf{1}$ (on next page)}

Correlations of Principal Components with eigenvalues greater than 1 (PCa and PCb) with each correlated behavioural variable measured.

PCa was strongly correlated with all behavioural variables included in the PCA, this correlation being positive with number of squares visited, number of square visits, and activity time, and negative with external squares visited ratio and external square visits ratio. $\mathrm{PCb}$ was negatively correlated with all behavioural variables included in the PCA, with weak or medium correlations. 


\section{Table 1:}

2 Correlations of Principal Components with eigenvalues greater than 1 (PCa and PCb) with

3 each correlated behavioural variable measured (number of squares visited, number of

4 square visits, external squares visited ratio, external square visits ratio, and activity time).

5

\begin{tabular}{|l|c|c|}
\hline Variable & PCa & PCb \\
\hline Number of squares visited & 0.888 & -0.292 \\
\hline Number of square visits & 0.850 & -0.412 \\
\hline External squares visited ratio & -0.790 & -0.578 \\
\hline External square visits ratio & -0.766 & -0.610 \\
\hline Activity time & 0.774 & -0.406 \\
\hline
\end{tabular}

6

7 


\section{Table 2 (on next page)}

Correlations of the Principal Component with an eigenvalue greater than 1 (PC1) with each correlated antipredator defence measured.

PC1 was strongly and positively correlated with both antipredator defences included in the PCA, namely parotoid gland relative area and relative sprint speed. 
1 Table 2:

2 Correlations of the Principal Component with an eigenvalue greater than 1 (PC1) with each 3 correlated antipredator defence measured (parotoid gland relative area and relative sprint 4 speed).

5

\begin{tabular}{|l|c|}
\hline Variable & PC1 \\
\hline Parotoid Gland Relative Area & 0.826 \\
\hline Relative Sprint Speed & 0.826 \\
\hline
\end{tabular}

6

7 